TẠP CHÍ KHOA HỌC ĐẠI HỌC TÂN TRÀO

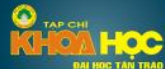

ISSN: $2354-1431$

http://tckh.daihoctantrao.edu.vn/

FOSTERING TEACHING CAPACITY FOR TEACHERS TO MEET THE REQUIREMENTS OF THE SECONDARY SCHOOL EDUCATION PROGRAM IN HA QUANG DISTRICT, CAO BANG PROVINCE IN 2018

Nguyen Quoc Hung ${ }^{1, *}$

${ }^{1}$ Department of Education and Training, Ha Quang District, Cao Bang Province, Vietnam

*Email address: quochungpgdtn@gmail.com

http://doi.org/10.51453/2354-1431/2021/639

\section{Article info}

Ngày nhận bài: 28/6/2021

Ngày duyệt đăng: 5/9/2021

\section{Keywords:}

Capacity; Teaching capacity; Nurturing teaching capacity

\begin{abstract}
:
The teaching capacity of teachers is a decisive factor in the quality of teaching, the secondary education program required teachers to continuously foster to update, supplement and improve their teaching capacity in 2018. The reality of fostering teaching capacity for teachers to meet the requirements of the secondary education program in Ha Quang district, Cao Bang province also revealed some limitations in content, methods, and forms of organization and implementation; Measures to change perception, content development, application of methods, and forms of training organization... It will contribute to improving the quality of teaching capacity building for teachers to meet the requirements of the secondary education program in Ha Quang district, Cao Bang province.
\end{abstract}


TẠP CHÍ KHOA HỌC ĐẠI HỌC TÂN TRÀO

ISSN: $2354-1431$

http://tckh.daihoctantrao.edu.vn/

\title{
BỒI DƯỡNG NĂNG LỰC DẠY HỌC CHO GIÁO VIÊN ĐÁP ỨNG YÊU CẦU CHƯƠNG TRİNH GIÁO DỤC THCS 2018 Ở HUYỆN HÀ QUẢNG, TỈNH CAO BẦNG
}

\author{
Nguyễn Quốc Hungl, * \\ ${ }^{1}$ Phòng Giáo dục Đào tạo huyện Hà Quảng,tỉnh Cao Bằng, Việt Nam \\ *Địa chi email: quochungpgdtn@gmail.com \\ http://doi.org/10.51453/2354-1431/2021/639
}

\section{Thông tin bài viết}

Ngày nhận bài: 28/6/2021

Ngày duyệt đăng: 5/9/2021

\section{Từ khóa:}

Năng lục; Năng lục dạy học; Bồi duõng năng lực dạy học

\section{Tóm tắt}

Năng lực dạy học của giáo viên là yếu tố quyết định chất lượng dạy học, chương trình giáo dục THCS 2018 đòi hỏi giáo viên phải bồi dưỡng để cập nhật, bổ sung, hoàn thiện năng lực dạy học; Thực trạng bồi dưỡng năng lực dạy học cho giáo viên đáp ứng yêu cầu chương trình giáo dục THCS ở huyện Hà Quảng, tỉnh Cao Bằng còn bộc lộ một số hạn chế về nội dung, phương pháp và hình thức tổ chức thực hiện; Các biện pháp thay đổi nhận thức, xây dựng nội dung, vận dụng phương pháp và hình thức tổ chức bồi dưỡng ... Sẽ góp phần nâng cao chất lượng bồi dưỡng năng lực dạy học cho giáo viên đáp ứng yêu cầu chương trình giáo dục THCS ở huyện Hà Quảng, tỉnh Cao Bằng

\section{1. Đặt vấn đề}

Giáo viên là nhân tố quyết định chất lượng dạy học, muốn nâng cao chất lượng dạy học phải thường xuyên nâng cao năng lực dạy học cho giáo viên. Năng lực dạy học của giáo viên phải thường xuyên được bổ sung, cập nhật để đáp ứng yêu cầu không ngừng đổi mới của giáo dục phổ thông [5].

Để đáp ứng yêu cầu thực hiện chương trình giáo dục phổ thông 2018, trong những năm qua, hoạt động bồi dưỡng năng lực dạy học cho đội ngũ giáo viên các trường trung học cơ sở huyện Hà Quảng, tỉnh Cao Bằng luôn được các cấp quản lý giáo dục chú trọng, tập trung vào các chuyên đề bồi dưỡng về đổi mới phương pháp và hình thức tổ chức dạy học vv...Tuy nhiên vẫn còn có những bất cập về nội dung, phương pháp và hình thức tổ chức thực hiện. Để khắc phục những hạn chế trên, cần có những nghiên cứu về động bồi dưỡng năng lực dạy học cho giáo viên THCS đáp ứng yêu cầu thực hiện chương trình giáo dục THCS 2018 ở huyện Hà Quảng, tỉnh Cao Bằng;

\section{Nội dung nghiên cứu}

\subsection{Cơ sở lý luận}

i) Khái niệm co bản và sụ cần thiết phải bồi duỡng năng lục dạy hoc cho giáo viên đáp úng yêu cầu chuoong trình giáo dục THCS 2018

Năng lực được định nghĩa theo rất nhiều cách khác nhau, tùy thuộc vào bối cảnh và mục đích sử dụng năng lực. Từ điển Giáo dục học, năng lực được hiểu là "khả năng được hình thành hoặc phát triển, cho phép một con người đạt thành công trong một hoạt động thể lực, trí lực hoặc nghề nghiệp" [2]. Đặng Thành Hưng, "năng lực là thuộc tính cá nhân cho phép cá nhân thực hiện thành công hoạt 
động nhất định, đạt kết quả mong muốn trong những điều kiện cụ thể” [3].

Nguyễn Quang Uẩn xem năng lực là "tổ hợp các thuộc tính độc đáo của cá nhân, phù hợp với những yêu cầu của một hoạt động nhất định, đảm bảo cho hoạt động đó có kết quả " [5]. Theo tác giả: "Năng lực là tổ hợp các thuộc tính tâm lý của cá nhân, được hình thành và phát triển trong một lĩnh vực hoạt động cụ thể. Là việc sở hữu kiến thức, kỹ năng, thái độ và đặc điểm nhân cách mà một người cần có để đáp ứng các yêu cầu của một nhiệm vụ cụ thể; nói cách khác, phải biết làm" [4]

Năng lực dạy học của giáo viên là tổ hợp thuộc tính tâm sinh lý và trình độ chuyên môn, nghiệp vụ sư phạm đã được chứng thực, chứng tỏ giáo viên hoàn thành một hoặc nhiều công việc theo chức năng, nhiệm vụ dạy học, giáo dục học sinh và chuẩn nghề nghiệp giáo viên.[ 4].

Bồi dưỡng năng lực dạy học cho giáo viên là quá trình bổ sung, nâng cao năng lực chuyên môn, nghiệp vụ và các kỹ năng tương ứng theo nội dung các năng lực dạy học cho giáo viên một cách thường xuyên để giúp họ cập nhật, trang bị thêm, trang bị mới những kiến thức, kỹ năng, thái độ làm tăng thêm năng lực, phẩm chất cho giáo viên đáp ứng nhiệm vụ dạy học trước yêu cầu đổi mới.

Chương trình giáo dục THCS 2018 đã đặt ra những vấn đề đổi mới dạy và học, cũng như yêu cầu mới về năng lực dạy học của người giáo viên. Phân tích chương trình giáo dục phổ thông 2018 cho thấy giáo viên THCS cần có những năng lực dạy học sau đây: Năng lực dạy học phát triển phẩm chất, năng lực học sinh trong môi trường dạy học đa văn hóa; Năng lực dạy học tích hợp liên môn, nội môn, dạy học theo hướng trải nghiệm; dạy học theo hướng giáo dục STEM; Năng lực dạy học phân hóa để thực hiện mục tiêu phát triển phẩm chất, năng lực học sinh theo năng lực chung và năng lực đặc thù; Năng lực phương pháp đó là năng lực vận dụng, phối hợp các phương pháp dạy học để phát triển phẩm chất, năng lực học sinh; Năng lực sử dụng công nghệ thông tin; ngoại ngữ, tiếng dân tộc trong dạy học ở trường THCS; Năng lực kiểm tra, đánh giá dạy học theo định hướng phát triển phẩm chất, năng lực học sinh; Năng lực phối hợp giữa nhà trường, gia đình và xã hội để tổ chức dạy học; Năng lực tư vấn, hỗ trợ học sinh trong học tập vv... Năng lực phát triển chương trình giáo dục nhà trường và chương trình môn học ở trường THCS [1];

ii) Mục tiêu bồi dữ̛ng năng lưc dạy học cho giáo viên trung học cơ sở theo chuoong trình giáo dục phổ thông 2018

Mục tiêu nhằm nâng cao năng lực dạy học cho giáo viên giúp giáo viên có nhận thức đúng về chương trình giáo dục THCS 2018; Đánh giá điểm khác biệt giữa chương trình giáo dục hiện hành với chương trình giáo dục 2018. Trên cơ sở đó nhận diện được những năng lực dạy học còn thiếu, còn yếu của bản thân để tích cực bồi dưỡng cập nhật, bổ sung hoàn thiện năng lực; iii)Nội dung bồi dưỡng năng lực dạy học cho giáo viên đáp ứng yêu cầu chương trình giáo dục THCS 2018: (1)Bồi dưỡng về CTGDPT 2018 và điểm khác biệt của chương trình;(2) Bồi dưỡng về năng lực dạy học tích hợp; (3) Bồi dưỡng năng lực dạy học phân hóa cho giáo viên; (4) Bồi dưỡng năng lực vận dụng, phối hợp các phương pháp dạy học theo định hướng phát triển năng lực học sinh;(5)Bồi dưỡng năng lực phát triển chương trình giáo dục nhà trường cho giáo viên THCS; (6)Bồi dưỡng năng lực đánh giá kết quả học tập của học sinh theo tiếp cận năng lực;(7)Bồi dưỡng năng lực ứng dụng công nghệ thông tin trong dạy học;(8)Bồi dưỡng năng lực tư vấn hỗ trợ học sinh;(9)Bồi dưỡng năng lực sử dụng ngoại ngữ và tiến dân tộc trong dạy học ở trường THCS cho giáo viên;

iv) Hình thức và phuoong pháp bồi duõng năng lục day học cho giáo viên trung học cor sở theo chuoong trình giáo duc phổ thông 2018

Phương pháp bồi dưỡng năng lực dạy học cho giáo viên phải là phương pháp dạy học cho người lớn, phát huy được vốn sống, vốn kinh nghiệm nghề nghiệp của giáo viên; phương pháp bồi dưỡng phải kết hợp giữa phương pháp nghiên cứu lý thuyết với phương pháp thực hành, tăng cường tính trải nghiệm thực tế của giáo viên nhằm giúp giáo viên thay đổi cách dạy và cách học của học sinh, trong đó coi trọng phương pháp tự bồi dưỡng, làm việc nhóm và thực hành nghề nghiệp của giáo viên; Các phương pháp bồi dưỡng có thể sử dụng trong hoạt động bồi dưỡng gồm các phương pháp sau:Phương pháp dạy học giải quyết vấn đề; Phương pháp dạy học thuyết trình; Phương pháp dạy học bằng tình huống; Phương pháp dạy học thực hành, dạy học qua trải nghiệm; Phương 
pháp thảo luận nhóm; Phương pháp nghiên cứu trường hợp vv...

Các hình thức bồi dưỡng cho giáo viên cần phong phú, đa dạng, linh hoạt dưới nhiều hình thức phù hợp với nội dung bồi dưỡng như: Hình thức tổ chức bồi dưỡng theo hình thức tập trung, trực tiếp; Hình thức tổ chức bồi dưỡng trực tuyến qua mạng; Hình thức tự bồi dưỡng có hướng dẫn qua tài liệu; Hình thức kết hợp giữa bồi dưỡng trực tiếp với bồi dưỡng trực tuyến;Hình thức bồi dưỡng tại chỗ: Sinh hoạt chuyên đề; nghiên cứu bài học; Hội thảo; dự giờ minh họa vv..Hình thức sinh hoạt chuyên môn; nghiên cứu chuyên đề theo nhóm trường, cụm trường vV...

v) Kiểm tra, đánh giá kết quả bồi duõng năng lực dạy học cho giáo viên trung học co' sở theo chuong trình giáo dục phổ thông 2018

Đánh giá kết quả việc bồi dưỡng qua việc theo dõi giám sát trong tất cả chương trình học tập. Trong quá trình đánh giá giáo viên thì kết quả của công tác bồi dưỡng cũng cần được sử dụng, như vậy hiệu quả của công tác bồi dưỡng mới đích thực có giá trị. Nội dung đánh giá: Đánh giá về mức độ tích cực của giáo viên khi tham gia bồi dưỡng; Đánh giá mức độ đạt được về kiến thức, kỹ năng của giáo viên so với mục tiêu bồi dưỡng đặt ra; Đánh giá về năng lực vận dụng của giáo viên trong triển khai các vấn đề mới do CTGDPT 2018 đặt ra. Phương pháp, hình thức đánh giá kết quả bồi dưỡng đa dạng, phong phú: Đánh giá kết quả làm việc của cá nhân; đánh giá kết quả làm việc nhóm; đánh giá bằng bài luận; thuyết trình; sản phẩm thực hiện nhiệm vụ thực hành vv...

2.2. Thục trạng về bồi dữóng năng lục dạy học cho giáo viên ở huyện Hà Quảng, tỉnh Cao Bằng đáp úng yêu cầu thục hiện chuơng trình giáo dục THCS 2018

\subsubsection{Phwơng pháp, khách thể khảo sát}

Sử dụng phương pháp điều tra bằng bảng hỏi, phỏng vấn sâu; nghiên cứu sản phẩm; Khảo sát được thực hiện trên 200 cán bộ quản lý của Phòng Giáo dục - Đào tạo; cán bộ quản lý trường THCS; giáo viên dạy trường THCS của huyện Hà Quảng; Cách xử lý số liệu được tính như sau : Các tiêu chí đánh giá 5 mức độ: Mức Tốt/Rất cần thiết/Rất khả thi/Rất quan trọng/Rất ảnh hưởng: 5 điểm ; Mức Khá/ cần thiết/khả thi/quan trọng/ảnh hưởng: 4 điểm ; Mức Trung bình/Tương đối cần thiết/ Tương đối khả thi/Tương đối quan trọng, Tương đối ảnh hưởng: 3 điểm; Mức Yếu / Ít cần thiết/Ít khả thi/Ít ảnh hưởng : 2 điểm; Mức Kém/ Không cần thiết/ Không khả thi / Không ảnh hưởng : 1 điểm.

Cách tính khoảng và xác định giá trị đo được

\begin{tabular}{|c|l|l|}
\hline Mức & \multicolumn{1}{|c|}{$\begin{array}{c}\text { Khoảng } \\
\text { điểm }\end{array}$} & \multicolumn{1}{c|}{ Mức đánh giá } \\
\hline 5 & $4.2-5.00$ & Tốt/Rất cần thiết/Rất khả thi /Rất ảnh hưởng \\
\hline 4 & $3.40-$ cận 4.20 & Khá/ cần thiết/khả thi/quan trọng/ảnh hưởng \\
\hline 3 & $2.60-$ cận 3.40 & $\begin{array}{l}\text { Trung bình/Tương đối cần thiết/ Tương đối khả thi/Tương đối quan trọng/ } \\
\text { Tương đối ảnh hưởng }\end{array}$ \\
\hline 2 & $1.80-$ cận 2.60 & Yếu/ Ít cần thiết/ Ít khả thi/Î́t ảnh hưởng \\
\hline 1 & $1.00-$ cận 1.80 & Kém/ Không cần thiết/ Không khả thi / Không ảnh hưởng \\
\hline
\end{tabular}

\subsubsection{Kết quả khảo sát}

i)Thưc trạng thục hiện mục tiêu bồi duõng năng lục dạy học cho giáo viên đáp úng yêu cầu chuoong trình giáo dục THCS 2018 ở huyện Hà Quảng, tỉnh Cao Bằng

Qua kết quả khảo sát từ cán bộ quản lý, giáo viên về mục tiêu bồi dưỡng năng lực dạy học cho giáo viên THCS theo chương trình giáo dục phổ thông 2018 ở huyện Hà Quảng, tỉnh Cao Bằng, tác giả nhận thấy nội dung "Nhận diện đúng về CTGD 2018” được đánh giá là thực hiện ở mức độ Khá với ĐTB = 3.75; nội dung “ Giáo viên tự giác tích cực bồi dưỡng, tự bồi dưỡng để hoàn thiện năng lực dạy học đáp ứng yêu cầu thực hiện chương trình giáo dục THCS 2018” được đánh giá thấp nhất so với các nội dung còn lại, ĐTB $=2.88$, mức độ đánh giá là “ Trung bình”. Kết quả khảo sát cho thấy việc thực hiện các mục tiêu bồi dưỡng năng lực dạy học cho giáo viên ở huyện Hà Quảng, tỉnh Cao Bằng đã được Phòng Giáo dục - Đào tạo huyện quan tâm triển khai thực hiện, tuy nhiên kết quả chỉ được đánh giá 
dừng ở mức khá là chủ yếu còn chỉ số mục tiêu thực hiện hoạt động bồi dưỡng được đánh giá ở mức trung bình đó là giúp giáo viên tự giác, tích cực bồi dưỡng để hoàn thiện năng lực dạy học đáp ứng yêu cầu thực hiện chương trình giáo dục THCS 2018, trong khi đó yếu tố này là yếu tố quan trọng, then chốt trong hoạt động bồi dưỡng giáo viên, bởi hoạt động bồi dưỡng năng lực dạy học cho giáo viên chỉ đạt được hiệu quả cao khi người giáo viên tự giác, tích cực tự bồi dưỡng. Trao đổi với giáo viên $\mathrm{H}$ trường THCS xã Ngọc Đào, tác giả được giáo viên cho biết do quá tải công việc giảng dạy, giáo dục học sinh đặc biệt là công tác vận động học sinh đến trường, giáo viên chưa quan tâm nhiều đến hoạt động tự bồi dưỡng để thực hiện CTGDPT 2018, mặt khác do tư duy mục đích gần chương trình chưa triển khai ngay phải đến năm học 2021 - 2022 mới bắt đầu triển khai nên giáo viên chưa đầu tư nhiều thời gian nghiên cứu để thực hiện CTGDPT 2018.

ii)Thục trạng nội dung bồi duõng năng lục dạy hoc cho giáo viênđáp úng yêu cầu chuơng trình giáo dục THCS 2018 ở huyện Hà Quảng, tỉnh Cao Bằng

Bảng 2.1. Nội dung bồi dưỡng năng lực dạy học cho giáo viên đáp ứng yêu cầu chương trình giáo dục THCS 2018 ở huyện Hà Quảng, tỉnh Cao Bằng

\begin{tabular}{|c|c|c|c|c|c|c|c|}
\hline \multirow{2}{*}{\multicolumn{2}{|c|}{ Nội dung bồi dưỡng }} & \multicolumn{5}{|c|}{ Mức độ thực hiện } & \multirow{4}{*}{$\begin{array}{l}\text { ФTB } \\
4.14\end{array}$} \\
\hline & & \multirow{2}{*}{1} & \multirow{2}{*}{$\begin{array}{l}2 \\
12\end{array}$} & \multirow{2}{*}{$\begin{array}{l}3 \\
6\end{array}$} & \multirow{2}{*}{$\begin{array}{l}4 \\
84\end{array}$} & \multirow{2}{*}{$\begin{array}{l}5 \\
88\end{array}$} & \\
\hline 1.Mục tiêu, nội dung chương trình giáo dục THCS & SL & & & & & & \\
\hline 2018 và tổ chức thực hiện & $\%$ & 5.0 & 6.0 & 3.0 & 42.0 & 44.0 & \\
\hline \multirow{2}{*}{ 2. Phát triển CTGD nhà trường } & SL & 17 & 15 & 11 & 83 & 74 & \multirow{2}{*}{3.91} \\
\hline & $\%$ & 8.5 & 7.5 & 5.5 & 41.5 & 37.0 & \\
\hline \multirow{2}{*}{ 3. Dạy học tích hợp, trải nghiệm, STEM } & SL & 50 & 43 & 32 & 32 & 43 & \multirow{2}{*}{2.88} \\
\hline & $\%$ & 25.0 & 21.5 & 16.0 & 16.0 & 21.5 & \\
\hline \multirow{2}{*}{ 4. Dạy học phân hóa } & SL & 21 & 20 & 58 & 48 & 53 & \multirow{2}{*}{3.46} \\
\hline & $\%$ & 10.5 & 10.0 & 29.0 & 24.0 & 26.5 & \\
\hline \multirow{2}{*}{$\begin{array}{l}\text { 5. Phương pháp, kỹ thuật dạy học hiện đại để phát } \\
\text { triển năng lực học sinh }\end{array}$} & SL & 30 & 27 & 67 & 36 & 40 & \multirow{2}{*}{3.15} \\
\hline & $\%$ & 15.0 & 13.5 & 33.5 & 18.0 & 20.0 & \\
\hline \multirow{2}{*}{$\begin{array}{l}\text { 6. Đánh giá kết quả dạy học theo định hướng phát } \\
\text { triển năng lực học sinh }\end{array}$} & SL & 18 & 20 & 52 & 53 & 57 & \multirow{2}{*}{3.56} \\
\hline & $\%$ & 9.0 & 10.0 & 26.0 & 26.5 & 28.5 & \\
\hline \multirow{2}{*}{ 7. Tư vấn hỗ trợ học sinh trong học tập } & SL & 21 & 32 & 27 & 63 & 57 & \multirow{2}{*}{3.52} \\
\hline & $\%$ & 10.5 & 16.0 & 13.5 & 31.5 & 28.5 & \\
\hline \multirow{2}{*}{$\begin{array}{l}\text { 8.Phối hợp nhà trường, gia đình và cộng đồng để tổ } \\
\text { chức dạy học }\end{array}$} & SL & 26 & 29 & 87 & 28 & 30 & \multirow{2}{*}{3.04} \\
\hline & $\%$ & 13.0 & 14.5 & 43.5 & 14.0 & 15.0 & \\
\hline \multirow{2}{*}{ 9. Úng dụng công nghệ thông tin trong dạy học } & SL & 18 & 16 & 34 & 62 & 70 & \multirow{2}{*}{3.75} \\
\hline & $\%$ & 9.0 & 8.0 & 17.0 & 31.0 & 35.0 & \\
\hline \multirow{2}{*}{$\begin{array}{l}\text { 10. Sử dụng ngoại ngữ hoặc tiếng dân tộc trong dạy } \\
\text { học }\end{array}$} & SL & 50 & 47 & 38 & 33 & 32 & \multirow{2}{*}{2.75} \\
\hline & $\%$ & 25.0 & 23.5 & 19.0 & 16.5 & 16.0 & \\
\hline \multirow{2}{*}{ 11. Các nội dung khác } & SL & 21 & 25 & 54 & 47 & 53 & \multirow{2}{*}{3.43} \\
\hline & $\%$ & 10.5 & 12.5 & 27.0 & 23.5 & 26.5 & \\
\hline
\end{tabular}

Kết quả khảo sát từ cán bộ quản lý, giáo viên về nội dung bồi dưỡng năng lực dạy học cho giáo viên đáp ứng yêu cầu thực hiện chương trình giáo dục THCS 2018 ở huyện Hà Quảng, tỉnh Cao Bằng, tác giả nhận thấy nội dung bồi dưỡng về : Mục tiêu, nội dung CTGD 2018 và yêu cầu tổ chức thực hiện được đánh giá với ĐTB $=4.14$ đạt kết quả thực hiện ở mức khá; Trao đổi với giáo viên $\mathrm{K}$ trường $\mathrm{THCS}$ thị trấn Hà Quảng, tác giả 
được biết với nội dung trên giáo viên đã được tập huấn theo chương trình tập huấn của Bộ dành cho giáo viên cốt cán và giáo viên đại trà, đồng thời được tập huấn qua triển khai thực hiện sách giáo khoa theo hình thức trực tiếp và trực tuyến.

Các nội dung đã triển khai bồi dưỡng năng lực dạy học cho giáo viên THCS huyện Hà Quảng được cán bộ quản lý và giáo viên đánh giá ở mức khá tiếp theo gồm các nội dung sau đây:Phát triển chương trình giáo dục nhà trường; Úng dụng công nghệ thông tin trong dạy học; Đánh giá kết quả dạy học theo định hướng phát triển năng lực học sinh; Dạy học phân hóa; Các nội dung đánh giá về thực hiện nội dung bồi dưỡng ở mức trung bình gồm các nội dung sau đây: Dạy học tích hợp, trải nghiệm, STEM; Sử dụng ngoại ngữ hoặc tiếng dân tộc trong dạy học; Phối hợp nhà trường, gia đình và cộng đồng để tổ chức dạy học;Trao đổi với thầy giáo $\mathrm{M}$ trường THCS thị trấn Thông Nông, tác giả luận văn được biết các nội dung về dạy học trải nghiệm, dạy học tích hợp, dạy học theo hình thức giáo dục STEM đã được Phòng Giáo dục - Đào tạo triển khai bồi dưỡng cho giáo viên tuy nhiên mức độ bao phủ nội dung chương trình môn KHTN theo CTGDPT 2018 chưa được nhiều mới chỉ tập trung vào một vài chủ đề dạy học trải nghiệm và tích hợp, do đó giáo viên còn tỏ ra lung túng trong triển khai các nội dung trên.

iv) Thực trạng phuoong pháp, hình thức bồi duõng năng lục dạy học cho giáo viên trung hoc co sở theo chuoong trình giáo duc phổ thông 2018 ơ huyện Hà Quảng, tỉnh Cao Bằng

Kết quả khảo sát cho thấy về cơ bản các phương pháp bồi dưỡng năng lực dạy học cho giáo viên THCS đã được các báo cáo viên đa dạng hóa, tuy nhiên một số phương pháp chiếm ưu thế nhằm nâng cao năng lực tự bồi dưỡng, bồi dưỡng tại chỗ chưa được Phòng Giáo dục; nhà trường THCS; báo cáo viên sử dụng thường xuyên.

Các hình thức tổ chức bồi dưỡng nâng cao năng lực dạy học cho giáo viên đã được đa dạng hóa, nhiều hình thức đã được triển khai và phối hợp với nhau, hình thức chiếm ưu thế và được sử dụng thường xuyên vẫn là hình thức bồi dưỡng trực tiếp và kết hợp giữa bồi dưỡng trực tiếp với bồi dưỡng trực tuyến điều này hoàn toàn phù hợp với chỉ đạo của Bộ Giáo dục Đào tạo về triển khai bồi dưỡng giáo viên thực hiện CTGDPT 2018. Tuy nhiên có một số hình thức bồi dưỡng thể hiện tính chủ động của giáo viên và nhà trường trong triển khai bồi dưỡng lại chưa được thực hiện một cách thường xuyên đó là: Hình thức bồi dưỡng trực tuyến qua mạng; Tự bồi dưỡng có hướng dẫn qua tài liệu hướng dẫn tự bồi dưỡng có sự hỗ trợ của giáo viên cốt cán; Hình thức bồi dưỡng theo cụm trường trên địa bàn; Hình thức bồi dưỡng tại chỗ qua các hoạt động chuyên môn tại trường THCS.

v) Đánh giá kết quả bồi duõng năng lục dạy học cho giáo viên trung họ cơ sở theo chuơng trình giáo dục phổ thông 2018 ở huyện Hà Quảng, tỉnh Cao Bằng

Qua kết quả đánh giá kết quả bồi dưỡng năng lực dạy học cho giáo viên trung học cơ sở theo chương trình giáo dục phổ thông 2018 ở huyện Hà Quảng, tỉnh Cao Bằng, tác giả nhận thấy nội dung “ Đánh giá sản phẩm cá nhân thông qua bài thu hoạch" được đánh giá là thường xuyên sử dụng nhất với ĐTB $=4.12$, mức độ đánh giá là “ Khá”, nội dung “ Đánh giá sản phẩm cá nhân thông qua hoạt động thực tế tại trường” được đánh giá thấp nhất so với các nội dung còn lại, ĐTB $=3.12$, mức độ đánh giá là “ Trung bình”.

2.2.3. Các biện pháp đề xuất bồi duỡng năng lục dạy học cho giáo viên

Nâng cao nhận thức cho cán bộ quản lý, giáo viên THCS về bồi dưỡng năng lực dạy học cho giáo viên theo chương trình giáo dục phổ thông 2018; Tổ chức khảo sát nhu cầu và xác định nội dung bồi dưỡng năng lực dạy học cho giáo viên trung học cơ sở theo chương trình giáo dục phổ thông 2018 ở huyện Hà Quảng, tỉnh Cao Bằng;Tổ chức đa dạng hóa hình thức bồi dưỡng năng lực dạy học cho giáo viên theo hướng phát huy vai trò tự bồi dưỡng của giáo viên đáp ứng yêu cầu thực hiện chương trình giáo dục THCS 2018; Phát triển đội ngũ giáo viên cốt cán hỗ trợ đồng nghiệp bồi dưỡng năng lực dạy học tại chỗ theo hình thức sinh hoạt chuyên môn tại trường hoặc theo cụm trường; Phát triển môi trường bồi dưỡng tạo động lực để giáo viên chủ động, tự giác, tích cực bồi dưỡng năng lực dạy học; Giám sát, đánh giá kết quả bồi dưỡng năng lực dạy học cho giáo viên trung học cơ sở theo chương trình giáo dục phổ thông 2018

\section{Kết luận}

Chương trình giáo dục THCS 2018 đặt ra yêu cầu mới về năng lực dạy học của người giáo viên, đòi hỏi giáo viên phải tích cực hoàn thiện năng lực dạy học; Qua khảo sát thực trạng cho thấy, hoạt động bồi dưỡng năng lực dạy học cho giáo viên THCS huyện 
Hà Quảng, tỉnh Cao Bằng đã đạt được những kết quả nhất định, tuy nhiên còn một số năng lực ở giáo viên còn hạn chế như năng lực dạy học tích hợp; dạy học theo định hướng phát triển năng lực; dạy học theo hướng trải nghiệm, giáo dục STEM; ...Phương pháp, hình thức tổ chức bồi dưỡng tại chỗ và tự bồi dưỡng của giáo viên chưa được quan tâm đúng mức. Vì vậy các cấp quản lý cần tăng cường bồi dưỡng năng lực dạy học cho giáo viên ở một số nội dung nêu trên để giúp giáo viên hoàn thiện năng lực dạy học; Giáo viên cần chủ động, tích cực tham gia các khóa đào tạo, bồi dưỡng để hoàn thiện năng lực cá nhân;

\section{REFERENCE}

[1] Viet Nam Ministry of Education and Training (2018); Circular No 32/2018/TT-BGDĐT, date 26/12/2018 Promulgate the Highchool Education Program.
[2] Hien, B., Nguyễn Van Giao, N.V., Quynh, N.H., Tao, V.V. (2001), Education Dictionary. Encyclopedia Dictionary Publishing House.

[3] Hung, D.T. (2012), Competence and education according to the capacity approach, Journal of Education Management, (43)

[4] Hung, N.Q. (2021); Managing activities of fostering teaching capacity for secondary school teachers under the 2018 general education program in Ha Quang district, Cao Bang province; Master Thesis, Thai Nguyen University of Education, Thai Nguyen University.

[5] Uan, N.Q., Toan, K.N. (2010), Innovative assessment of learning in Australian universities, Scientific report at the conference on Researching and teaching social sciences at Pedagogical Universities in the process of international integration, Hanoi National University of Education 